\title{
FAKTOR YANG BERKONTRIBUSI DALAM PEMANFAATAN POSBINDU
}

\author{
Nina Sumarni, \& Witdiawati \\ Staf Dosen Fakultas Keperawatan UNPAD Bandung \\ Email: n.sumarni@unpad.ac.id
}

\begin{abstract}
Abstrak
Meningkatnya umur harapan hidup penduduk berdampak pada meningkatnya jumlah penduduk yang berusia lanjut. Pemeliharaan kesehatan bagi lansia dilakukan dengan berbagai upaya, diantaranya melalui kegiatan pemberdayaan masyarakat yang melibatkan keluarga dan masyarakat setempat. Posbindu Cendrawasih merupakan satu-satunya posbindu yang berada di wilayah kerja Puskesmas Cipanas Garut, dengan jumlah lansia 126 orang. Cakupan pelayanan posbindu di Puskesmas Cipanas Garut masih rendah $(30,2 \%)$ dari target $70 \%$. Tujuan penelitian ini untuk mengetahui faktor apa yang berkontribusi dalam pemanfaatan posbindu di Posbindu Cendrawasih Wilayah Kerja Puskesmas Cipanas Garut Tahun 2016. Penelitian ini merupakan penelitian deskriptif kuantitatif. Ukuran sampel yang digunakan adalah sampel populasi yaitu 126 responden. Pengumpulan data menggunakan kuesioner yang telah diuji validitas dan reliabititasnya. Analisa penelitian dilakukan sampai analisa univariat. Hasil penelitian menunjukan sebagian besar pengetahuan lansia dalam kategori kurang $(50,78 \%)$, lansia bersikap negatif (62,78\%), dukungan keluarga yang rendah (66,67\%). Tindakan atau perilaku manusia dibentuk oleh keturunan, lingkungan dan pengetahuan. Sikap yang terbentuk tidak dapat diubah begitu saja karena sangat erat kaitanya dengan faktor dalam dan luar individu. Dukungan keluarga merupakan faktor penguat untuk terjadinya perilaku kesehatan. Puskesmas perlu melakukan pendidikan kesehatan yang berkesinambungan mengenai pentingnya posbindu sebagai sarana untuk memenuhi kebutuhan kesehatan lansia.
\end{abstract}

Kata kunci: Posbindu, pengetahuan, sikap, dukungan keluarga.

\begin{abstract}
Abstrac
The increasing life expectancy of the population has an impact on the increasing number of elderly people. Health care for the elderly is done with various efforts, including through community empowerment activities involving families and local communities. Posbindu Cendrawasih is the only posbindu in the working area of Cipanas Garut Public Health Center, with a total of 126 people. Posbindu service coverage in Cipanas Garut Health Center is still low (30.2\%) from the target of $70 \%$. The purpose of this study is to find out what factors contribute to the utilization of posbindu in Posbindu Cendrawasih Work Area of Cipanas Garut Public Health Center in 2016. This research is a quantitative descriptive study. The sample size used is a population sample of 126 respondents. Data collection using a questionnaire that has been tested for validity and reliability. Analysis of the research was carried out until univariate analysis. The results showed that most of the elderly's knowledge in the category was less (50.78\%), the elderly were negative (62.78\%), family support was low (66.67\%). Human actions or behavior are formed by descent, environment and knowledge. The attitude that is formed cannot be changed simply because it is very closely related to internal and external factors of the individual. Family support is a reinforcing factor for the occurrence of health behavior. The Puskesmas needs to conduct sustainable health education regarding the importance of posbindu as a means to meet the health needs of the elderly.
\end{abstract}

Keywords: Posbindu, knowledge, attitude, family support. 


\section{PENDAHULUAN}

Meningkatkan umur harapan hidup penduduk berdampak pada meningkatnya jumlah penduduk yang berusia lanjut dan bertambah cenderung lebih cepat. Menurut WHO pada tahun 2010 persentasi lansia di dunia $9,11 \%$ dari jumlah penduduk dunia, di Indonesia tahun 2010 jumlah populasi lansia usia 60 tahun keatas $9,77 \%$, estimasi tahun 2020 jumlah populasi lansia sebanyak 28.8 juta, di tahun 2025 seperlima penduduk Indonesia adalah lansia (Badan Pusat Statistik, 2009). Meningkatnya umur harapan hidup (UHH) adalah salah satu indikator tingkat kesehatan masyarakat. Semakin tinggi jumlah lansia, maka makin baik tingkat kesehatan masyarakatnya. Konsekuensi logis dari keadaan tersebut ialah permasalahan yang dihadapi para lansia akan semakin besar dan komplek, serta telah menjadi fenomena nasional yang perlu mendapat perhatian kita semua.

Pemeliharaan kesehatan bagi lansia dilakukan melalui pemberdayaan masyarakat yang melibatkan keluarga dan masyarakat, serta kemitraan dengan LSM dan swasta, pembinaan dengan pendekatan holistik melalui pelayanan dasar dengan sistem yang berkualitas. Sebagai wujud nyata pelayanan sosial dan kesehatan pada kelompok lansia, Pemerintah telah mencanangkan pelayanan pada lansia melalui beberapa jenjang pelayanan kesehatan di tingkat masyarakat adalah posyandu lansia. Seperti yang tercantum dalam UU No 36 tahun 2009 tentang kesehatan, dimana pada pasal 19 dan peraturan Mentri Dalam Negeri No 54 tahun 2007 tentang Pembangunan Posyandu. Disebutkan bahwa manusia usia lanjut diarahkan memiliki, membantu penyelenggaraan upaya kesehatan usia lanjut untuk meningkatkan kualitas hidupnya secara optimal.

Melalui kegiatan posbindu rasa kebersamaam dan semangat hidup para lanjut usia dapat dipupuk melalui serangkaian kegiatan jasmani maupun rohani, antara lain saling silaturahmi, kegiatan olah raga, keagamaan dan ketrampilan melalui kegiatan posbindu lansia diharapkan dapat memberikan kemudahan bagi lansia dalam memperoleh pelayanan kesehatan dasar, agar kualitas hidup masyarakat usia di usia lanjut tetap terjaga dengan baik. Dengan dicanangkan program posbindu tersebut dengan baik agar kesehatan para lansia dapat terpelihara dan terpantau secara optimal. Namun pada kenyataannya tidak semua lansia memanfaatkan adanya kegiatan posbindu tersebut. Rendahnya pemanfaatan posbindu dipengaruhi oleh sikap dan perilaku lansia.

Menurut para ahli ada berbagai faktor yang dapat mempengaruhi pemanfaatan posbindu diantaranya pengetahuan, sikap, dukungan keluarga, pekerjaan, pendidikan dan jenis kelamin. Lansia yang tidak memanfaatkan posbindu memiliki proporsi pengetahuan yang rendah, dan hubungan bermakna antara pengetahuan dengan pemanfaatan posbindu.

Selain itu penelitian yang dilakukan oleh Lestari (2005) yang menyebutkan bahwa ada hubungan yang bermakna sikap dengan pemanfaatan posbindu, ada perbedaan proporsi sikap negatif $(85,2 \%)$ yang dimiliki responden yang tidak memanfaatkan posbindu. Tujuan penelitian ini adalah untuk mengetahui faktor-faktor yang berkontribusi dalam pemanfaatan Posbindu.

\section{METODE PENELITIAN}

Rancangan penelitian dilakukan dengan menggunakan pendekatan deskriptif kuantitatif. Populasi penelitian adalah semua lansia peserta Posbindu yang bertempat tinggal di wilayah Cipanas Garut. Besar sampel dalam penelitian ini adalah sampel populasi yaitu 126 orang atau mengunakan total sampling. Instrumen penelitian 
menggunakan kuesioner dalam bentuk pertanyaan tertutup dan telah diuji validitas serta reliabititasnya. Semua data yang telah terkumpul diolah dan dianalisis secara univariat.

\section{HASIL DAN PEMBAHASAN}

Tabel 1. Distribusi Frekuensi Tingkat

Pengetahuan Lansia dalam Pemanfaatan Posbindu

\begin{tabular}{cccc}
\hline No & Pengetahuan & Frekuensi & $\%$ \\
\hline 1 & Baik & 44 & 34,93 \\
\hline 2 & Cukup & 18 & 14,29 \\
\hline 3 & Kurang & 64 & 50,78 \\
\hline & Jumlah & 126 & 100 \\
\hline
\end{tabular}

Berdasarkan table 1 di atas, pengetahuan lansia mengenai pemanfaatan posbindu sebagian besar dalam kategori kurang, 64 responden (50,78\%). Kondisi tersebut mencerminkan bahwa lansia di wilayah kerja Posbindu Cendrawasih pada umumnya belum memiliki pengetahuan yang memadai mengenai Posbindu. Sama dengan hasil penelitian Viena dengan hasil penelitian pengetahuan kurang sebanyak 18 orang $(22,2 \%)$. Tetapi berbeda dengan hasil penelitian yang dilakukan oleh Marlina (2013) dimana sebagian besar responden memiliki pengetahuan tinggi tentang posbindu sebanyak 52 responden $(71,7 \%)$. Begitu juga dengan hasil penelitian Noucie dan Sari (2011) dimana sebagian besar responden berpengetahuan baik mengenai posbindu sebanyak 23 orang $(37,7 \%)$.

Berdasarkan hasil penelitian pengetahuan para lansia kurang mengenai manfaat Posyandu lansia ini akan berdampak terhadap kurangnya pemahaman lansia dalam memanfaatkan Posbindu lansia, keterbatasan pengetahuan ini akan mengakibatkan kurangnya kunjungan para lansia pada Posbindu sehingga pemantauan dan pemeliharaan kesehatan para lansia akan terbengkalai.Responden yang memiliki pengetahuan yang baik banyak yang memanfaatkan posbindu. Sedangkan yang berpengetahuan kurang banyak diantaranya kurang memanfaatkan posbindu. Oleh karena itu semakin baik pengetahuan tentang pemanfaatan posbindu maka akan semakin baik dalam keikutsertaan lansia dalam pemanfaatan posbindu.

Tabel 2. Distribusi Frekuensi Sikap Lansia Dalam Pemanfaatan Posbindu

\begin{tabular}{cccc}
\hline No & Sikap & Frekuensi & $\%$ \\
\hline 1 & Positif & 47 & 37,30 \\
\hline 2 & Negatif & 79 & 62,78 \\
\hline & Jumlah & 126 & 100 \\
\hline
\end{tabular}

Berdasarkan table 2., sikap lansia dalam pemanfaatan posbindu sebagian besar dalam kategori negatif yaitu sebanyak 79 responden lansia. Data tersebut mencerminkan bahwa lansia di wilayah Posbindu Cendrawasih pada umunya belum memiliki sikap positif dalam pemanfaatan posbindu. Sama dengan hasil penelitian yang dilakukan oleh Noucie dan Sari (2011) bahwa dari 61 lansia sebagian besar mempunyai sikap yang negatif mengenai Posbindu di RW 07 Desa Kertawangi Kecamatan Cisarua Kabupaten Bandung Barat sebanyak 32 orang (52,5\%). Berbeda dengan hasil penelitian Viena (2015) jumlah responden yang memiliki sikap yang baik sebanyak 55 orang $(67,9 \%)$, begitu juga hasil penelitian yang dilakukan oleh Pitayanti (2017) sebanyak 39 responden $(55,7 \%)$ responden lansia mempunyai sikap positif. Responden yang mempunyai sikap positif seharusnya sudah mampu memanfaatkan posbindu sebagai suatu wadah pelayanan dalam rangka pemantauan dan pemeliharaan kesehatan para lansia.

Menurut Notoatmodjo (2010) sikap, tindakan dan respon internal setelah adanya pemikiran, sikap batin, tanggapan dan pengetahuan. Tindakan atau perilaku 
manusia ini dipengaruhi oleh keturunan, lingkungan dan pengetahuan. Sikap yang terbentuk tidak dapat diubah begitu saja karena sangat erat kaitanya dengan faktor dalam dan luar individu. Maka untuk merubah sikap responden diperlukan suatu kebijakan dan peningkatan pengetahuan agar para lansia dapat mengetahui tujuan dan manfaat serta hasil yang didapatkan dari memanfaatkan posbindu.

Tabel 3. Distribusi Frekuesni Dukungan Keluarga dalam Pemanfaatan Posbindu

\begin{tabular}{cccc}
\hline No & Dukungan & Frekuensi & $\%$ \\
\hline 1 & Positif & 42 & 34,33 \\
\hline 2 & Negatif & 84 & 66,67 \\
\hline & Jumlah & 126 & 100 \\
\hline
\end{tabular}

Berdasarkan table 3., dukungan keluarga lansia dalam pemanfaatan posbindu sebagian besar kategori negative atau kurang mendukung, sebanyak 84 responden $(66,67 \%)$. Hasil penelitian sama dengan yang dilakukan Khasanah (2016), dimana dukungan keluarga sebagian besar kurang baik $(62,9 \%)$. Begitu juga hasil penelitian yang dilakukan oleh Safarach dimana hasil penelitiannya ditemukan lebih dari setengah responden (53,2\%) tidak memiliki dukungan keluarga. Demikian juga hasil penelitian Bratanagara (2012), lebih dari setengah responden $(53,2 \%)$ keluarga yang tidak mendukung. Ini berbeda dengan hasil penelitian Viena (2015) responden yang memiliki dukungan keluarga sebanyak 55 orang $(67,9 \%)$. Begitu juga hasil penelitian Purnayanti (2014) dukungan keluarga merupakan salah satu faktor yang mempengaruhi kunjungan lansia ke posbindu.

Hasil penelitian mencerminkan bahwa lansia di wilayah kerja Posbindu Cendrawasih pada umumnya belum mendapat dukungan yang baik dari keluarga dalam pemanfaatan posbindu. Dukungan keluarga merupakan suatu proses yang terjadi sepanjang hidup, dimana melalui dukungan keluarga didalamnya terdapat sebuah informasi, saran, bantuan nyata dan sikap yang diberikan oleh keluarga dan orang terdekat.

Sikap akan membuat seseorang mendekati atau menjauhi orang lain atau objek lain. Faktor-faktor yang mempengaruhi sikap diantaranya pengalaman pribadi, kebudayaan, media masa, pendidikan, emosi. Rendahnya pemanfaaatan pelayanan kesehatan dipengaruhi oeh fasilitas dan pelayanan kesehatan yang diberikan di Posbindu. Keberadaan dukungan dari keluarga sangat berpengaruh dalam hubungan sosial lanjut usia. Faktor penguat untuk terjadinya perilaku kesehatan adalah dorongan anggota keluarga.

\section{KESIMPULAN}

Faktor yang berkontribusi dalam pemanfaatan Posbindu di Posbindu Cendrawasih wilayah kerja Puskesmas Cipanas Garut didominasi oleh pengetahuan lansia yang kurang, sikap lansia yang negatif, dan kurangnya dukungan keluarga lansia. Puskesmas Cipanas Garut perlu melakukan pendidikan kesehatan yang berkesinambungan mengenai pentingnya posbindu sebagai sarana untuk memenuhi kebutuhan kesehatan lansia.

\section{DAFTAR PUSTAKA}

Bratanegara, A. S., (2012). Gambaran Dukungan Keluarga Terhadap Pemanfaatan Posbindu Lansia Kelurahah Karasak Kota Bandung. Students e-Journal, 1(1), 28.

Dinas Kesehatan Kabupaten Garut (2016): Profil Kesehatan Kabupaten Garut

Khasanah, U. (2016). Hubungan Faktor

Personal Dan Dukungan Keluarga Dengan Manjemen Diri Penderita Diabetes Mellitus Di Posbindu Wilayah Kerja Puskesmas Pisangan Kota Tangerang Selatan.

Maryam, R., Ekasari, Batubara, M., (2008). Mengenal Usia Lanjut dan 
Perawatannya, Jakarta, Salemba Medika.

Marlina, L. (2013). Hubungan Tingkat Pengetahuan Lansia Tentang Posbindu dengan Motivasi Lansia Mengunjungi Posbindu.

Notoatmodjo S. (2003). Pendidikan dan Perilaku Kesehatan, Jakarta, Rieneka Cipta.

Notoatmodjo, S. (2007). Promosi Kesehatan dan Ilmu Perilaku, Rieneka Cipta.

Noucie, dan Sari W.E., (2011). Hubungan pengetahuan dengan sikap lansia mengenai Posbindu di Rw 07 Desa Kertawangi Kecamatan Cirasua Kabupaten Bandung. TA Stikes A. Yani Cimahi.

Purnawati, N. (2014). Faktor-Faktor Yang Mempengaruhi Kunjungan Lansia Dalam Kegiatan Posyandu Di Desa Plumbon Kec. Mojolaban Sukoharjoul (Doctoral dissertation, Universitas Muhammadiyah Surakarta)
Pitayanti, A. (2017). Sikap lansia dan Pelayanan Petugas Kesehatan Terhadap kunjungan di Posyandu Wilayah PKM Patihan. Warta Bhakti Husada Mulia,4(2) Septriliyana, N. (2011). Hubungan Pengetahuan Dengan Sikap Lansia Mengenai Posbindu di RW 07 Desa Kertawangi Kecamatan Cisarua Kabupaten Bandung Barat Tahun 2011. Jurnal Kesehatan Kartika, 2(1), 43-9.

Viena, M.V., (2015). Pemanfaatan Posyandu Lansia di Wilayah Kerja Puskesmas Teling Atas Kota Manado. JIKMU, 5(5).

Wahyuni, D. N., (2017). Faktor-Faktor yang Berhubungan dengan Kunjungan Pos Pembinaan Terpadu (Posbindu pada Lansia) di Wilayah Kerja Puskesmas Ciputat. Bachelor's thesis, UIN Syarif Hidayatullah. Jakarta: Fakultas Kedokteran dan IImu Kesehatan 